\title{
The effects of vitamins and trace minerals on chronic autoimmune thyroiditis
}

\author{
Małgorzata Włochal, Marcin A. Kucharski, Marian Grzymisławski
}

Department of Internal Diseases, Metabolic Disorders and Nutrition, Poznan University of Medical Sciences, Poland

\begin{abstract}
Hashimoto's thyroiditis (HT), also known as chronic lymphocytic thyroiditis is one of the most frequent types of inflammation of the thyroid gland. The prevalence of the overt $\mathrm{HT}$ is about $2 \%$ but it is believed that Hashimoto thyroiditis is more frequent than expected. Hashimoto's thyroiditis is characterized by dysfunction of the immune system, which leads to impaired tolerance of own tissues and increased production of autoantibodies against the thyroid cells. Thyroid peroxidase antibodies (anti-TPO), thyroglobulin antibodies (anti-Tg) and/or TSH receptors antibodies are the principal markers of the disease. The essential element of the treatment of HT is the supplementation of L-thyroxine. In Hashimoto's disease, like in many other autoimmune diseases, researchers attempted to support pharmacological treatment by adequate nutrition. The aim of this paper was to review the existing literature on the levels of antioxidants (vitamin A, C, E, selenium, zinc) and vitamin D in patients with HT, as well as the influence of the nutritional supplementation of the above mentioned elements on the metabolism of the thyroid gland hormones and the level of anti-thyroid peroxidase (anti-TPO) antibodies.
\end{abstract}

Keywords: Hashimoto's thyroiditis, antioxidants, vitamin D, selenium, vitamins and trace minerals supplementation.

\section{Introduction}

Hashimoto's thyroiditis also know as chronic lymphocytic thyroiditis is the most frequent type of inflammation of the thyroid gland. Although the disease has been described more than 100 years ago, it is still not fully understood.

Hashimoto's thyroiditis is characterized by dysfunction of immune system, which leads to impaired tolerance of own tissues and the increased production of autoantibodies against thyroid cells. Thyroid peroxidase antibodies (anti-TPO), thyroglobulin antibodies (anti-Tg) and/or TSH receptors antibodies are the principal markers of the disease. In addition HT revealed lymphocytic infiltration which destroys thyroid follicular cells. The concentration of free thyroxine (FT4) and free triiodothyronine (FT3) in patients with Hashimoto's disease is reduced. HT is the most frequent type of hypothyroidism. The prevalence of the overt HT is about $2 \%$ but it is believed that Hashimoto's thyroiditis is more frequent than expected [1]. The incidence rate of HT is estimated at $0.3-1.5 / 1,000$ cases per year. Chronic autoimmune thyroiditis may occur in all age groups, also in children. The peak incidence is between 45 and 65 years of age. Women suffer from HT 10-20 times more frequently than men, which confirms the participation of estrogen in the development of the disease [2]. HT develops slowly, starting without any symptoms. In the initial phase of the disease may mild, temporary hyperthyroidism occur, which after a short period of euthyroid state changes into permanent hypothyroidism. There are many causes recognized in the etiology of the disease such as: environmental factors (nicotine, iodine and selenium intake, drugs, pollution), physiological state of the organism (pregnancy, menopause, emotional and physical stress), genetic factors (specific HLA allele, polymorphisms of PTPN22 and thyroglobulin gene), bacterial and viral infections, female sex, and age $[2,3,4]$. Treatment of Hashimoto disease involves 
L-thyroxine supplementation (1-2 mcg/ $\mathrm{kg} / \mathrm{day})$ in order to normalize TSH and FT4 concentrations. In Hashimoto, like in many other autoimmune diseases, researchers attempted to support pharmacological treatment by adequate nutrition. Existing publications focused on vitamins and trace minerals supplementation in patients with Hashimoto disease. The aim of this paper was to review the literature on antioxidants (vitamin $A, C, E$, selenium, zinc) and vitamin D supplementation in HT and to assess its immunomodulatory effects and influence on metabolism of the thyroid gland hormones.

\section{Antioxidant vitamins and trace minerals in Hashimoto's disease}

Autoimmune Hashimoto's thyroiditis is associated with impaired antioxidant status and detrimental action of oxidants and free radicals. Enzymatic and non-enzymatic mechanisms play an important role in counteracting the harmful effects of the reactive oxygen species. The results of studies evaluating the effect of hypothyroidism on the body's antioxidant status are poor and inconsistent. Study conducted by Erdamar [5] the effects of hypo- and hyperthyroidism and treatment of those conditions on the antioxidant status markers revealed an increased generation of reactive oxygen species and impairment of the antioxidant system in patients with hyper- and hypothyroidism. This was seen particularly in patients with hypothyroidism. Similarly, Reddy's study [6] conducted on 72 patients with subclinical or overt hypothyroidism showed, that the malondialdehyde (MDA) and glutathione peroxidase (GPX) values were elevated, while glutathione (GSH), ferric reducing ability of plasma (FRAP) and superoxide dismutase (SOD) were decreased in both patient groups compared with controls. No change in activities of catalase (CAT) and glutathione reductase (GR) were observed in both patient groups. One of the recent studies [7] in this field indicated significant differences in the levels of glutathione (GSH), glutathione peroxidase (GPx) in patients with newly diagnosed HT as compared to the control group $(P<0.001)$. Since the activity of some antioxidant enzymes depends on the availability of copper, zinc (SOD) and selenium (GPx) it should come to mind, that changes in the concentration of these trace minerals (resulting from the pathophysiology of the disease) may affect the ability to defend against reactive oxygen species.

Zinc is an essential trace element for the conversion of thyroxine to triiodothyronine. Previous study [8] suggested that zinc deficiency leads to a reduction in the level of FT4 and FT3 and development of hypothyroid- ism symptoms. Existing studies did not examine the relationship between the occurrence of zinc deficiency and the risk of Hashimoto's disease. The study conducted by Erdal et al. [9] to evaluate the serum copper, zinc, magnesium, and selenium in patients with subclinical hypothyroidism did not confirm association between thyroid function and zinc level. Similarly, Przybylik-Mazurek et al. found no differences in copper, zinc, and $\mathrm{Zn} / \mathrm{Cu}$ ratio between Hashimoto patients and control group [10]. Furthermore, the results of study [11] on the effects of zinc supplementation and thyroid hormone concentrations were not clear. A study conducted by Pathak [12] which evaluated the influence of zinc supplementation on the abnormal serum levels of triiodothyronine (FT3), thyroxine (FT4) (decreased) and thyroid-stimulating hormone (TSH) (increased) in male Wistar rats revealed, that 8 week administration of zinc regulated the T3, T4 and TSH concentrations. However, clinical research did not confirm that zinc supplementation in humans without substantial zinc deficiencies leads to regulation of thyroid hormone metabolism [13].

In addition to the enzymatic mechanisms, an important role in antioxidant defense is played by exogenous antioxidants like vitamin A, C, and E, which are delivered to the body with food. L-tocopherol, the most biologically active and most widespread vitamin $E$ form in the body has a protective effect on cell membranes. As an antioxidant, vitamin $\mathrm{E}$ acts as a free radical scavenger, it inhibits lipid peroxidation and causes the extinction of singlet oxygen. Vitamin C (L-ascorbic acid) is involved in the reduction of tocopherol, hydroxyl radicals and reactions with superoxide anion. Animal study [14] which assessed the effects of antioxidants against methimazole (MMI) induced hypothyroidism in male Wistar rats showed benefits of supplementation with vitamins $C$ and $E$ for the thyroid gland. The rats who received vitamins $\mathrm{C}$ and $\mathrm{E}$ along with $\mathrm{MMI}$ showed statistically significant reduced weight (38-55\% less) of the thyroid glands $(P<0.01)$ and less suppressed FT4 and FT3 levels (2-6\% and $7-35 \%$ respectively) as compared to the controls. Other experimental study [15] indicated the influence of vitamin $\mathrm{E}$ supplementation on the reduction of malondialdehyde level in the group of male Sprague Dawley rats with propylthiouracilinduced hypothyroidism. Additionaly, vitamin E supplementation significantly increased liver and kidney reduced glutathione levels.

A different result was obtained in the study conducted by Adali et al. [16], who found no beneficial effects of vitamin $E$ supplementation on the antioxidant status in patients with hypothyroidism. 
Vitamin A has the ability to directly react with free radicals, scavenging lipid peroxides and singlet oxygen. Moreover, it plays an important role in the regulation of thyroid hormone metabolism and the inhibition of TSH secretion. So far, only a few studies evaluated the effect of vitamin A supplementation on thyroid function and treatment of Hashimoto's disease. A 4-month randomized, double blind controlled trial conducted by Farthang et al. [17], on 84 premenopausal women (56 women with obesity) showed, that vitamin A supplementation (25,000 IU/d retinyl palmitate) significantly reduced the serum TSH concentrations ( $p=0.004$ ), therefore it might reduce the risk of subclinical hypothyroidism in premenopausal women. Another study [18] demonstrated that the supply of vitamin A alone or in combination with iodine had a positive effect on the functioning and size of the thyroid gland.

It was previously suggested, that high levels of antiTPO are associated with deficiency of antioxidant vitamins $(E, A, C)$, trace mineral (Se) as well as iron and copper, which are important antioxidant enzyme cofactors. This thesis was not confirmed by Dellal et al. in their study [19], in which no relationship was observed between the levels of vitamin E, A, D, folate, Fe, Cu, Se and the occurrence of Hashimoto's disease. The study demonstrated the existence of a negative correlation between the concentration of vitamin B12 and the antiTPO level (despite the absence of vitamin B12 deficiency). This generates the necessity to screen patients with HT for atrophic gastritis. Earlier studies [20, 21] on the relationship between thyroid dysfunction and levels of vitamin B12 showed that $7-12 \%$ of patients with HT suffer from pernicious anemia, therefore the concentration of cobalamin should be evaluated every 3 to 5 years. The study [22] on a large population (1,401 subjects) with mild and severe thyroid dysfunction indicated no correlation between the levels of zinc, selenium, vitamin $C$ and the markers of thyroid gland function although, Moncayo et al. found, that the percentage of patients whose levels of vitamin C, zinc and selenium were below the reference values amounted to, respectively $8.7 \%, 7.8 \%$ and $20.3 \%$.

Selenium is a necessary trace mineral for humans because of its antioxidant and anti-inflammatory properties. It is present in specific selenoproteins such as glutathione peroxidase (GSH), iodothyronine deiodinase and thioredoxin reductases (TRs). Selenium plays a major role in the thyroid hormone metabolism by conversion of triiodothyronine (T3) to tetraiodothyronine (FT4). The recommended daily intake of selenium varies from $55-70 \mu \mathrm{g}$ depending on the geograph- ic region (55 $\mu \mathrm{g} /$ day in the USA, 60-70 $\mu \mathrm{g}$ in England, $1 \mu \mathrm{g} / \mathrm{kg}$ of body weight per day in France). Exceeding the dosage of $400 \mu \mathrm{g}$ per day is toxic and leads to selenosis. The best food sources of selenium are meat, fish, shellfish, offal, eggs, cereals. Even a mild zinc deficiency can result in an increased risk of the development and progression of autoimmune thyroid disease.

Several previous studies confirmed that serum selenium level in patients with HT was lower than in the healthy control group. According to the Polish research [23] the average content of Se in serum of patients with Hashimoto disease $(63.03 \pm 17.31 \mu \mathrm{g} / \mathrm{L})$ was significantly lower $(p<0.0007)$ in comparison with the control group $(75.16 \pm 19.92 \mu \mathrm{g} / \mathrm{L})$. Similarly, Erdal et al. [24] revealed lower levels of selenium in serum of patients with Hashimoto's thyroiditis $(67.7 \pm 10.4$ $\mathrm{mg} / \mathrm{l})$ as compared to the control group (83.7 \pm 17.3 $\mathrm{mg} / \mathrm{l})$. It appeares that in the publications demonstrating the benefits of selenium supplementation in autoimmune diseases, many of the studies focused on examining the effect of selenium supplementation on the course of HT, in particular the normalization of thyroid gland hormone levels and the reduction of anti-TPO concentrations. These results were not conclusive $[25,26]$. One of the earliest studies [27] in this field revealed, that in patients with Hashimoto's disease selenium supplementation decreased anti-thyroid antibody levels and improved the ultrasound structure of the thyroid gland.

Several clinical studies in patients with autoimmune thyroid disease demonstrated, that the 6 month long Se supplementation (200 micrograms) caused an increase in serum selenium level from $70-75 \mathrm{mg} / \mathrm{l}$ to 86-125 mg/l, which can cause better functioning of the thyroid gland [23].

Similarly, study conducted by Zhu et al. [28] in 2012 on autoimmune thyroiditis patients with different thyroid functional status, revealed that selenium supplementation with $200 \mathrm{mg}$ for 6 months resulted in the reduction of anti-TPO concentration (12.6\% in subclinical and $20.4 \%$ in the overt form of the disease). Five other studies [29-33] on the effect of selenium supplementation on HT confirmed, that the selenium intake in a dose of 100 to $200 \mathrm{mg} /$ day for 3-12 months decreased the anti-TPO but did not cure the underlying autoimmune thyroid disease. In a blinded, placebo-controlled trial, Gärtner et al. [34] observed, that in the group of HT females receiving 200 micrograms (2.53 micromol) sodium selenite per day, orally for 3 months, the mean anti-TPO concentration decreased significantly ( $63.6 \%$ vs. $88 \%$ in the placebo group). 
Moreover, patients with anti-TPO greater than 1200 $\mathrm{IU} / \mathrm{ml}$ revealed a mean $40 \%$ reduction in anti-TPO concentrations, as compared with a $10 \%$ increase in antiTPO in the placebo group. The mean TSH, FT4, and FT3 levels were unchanged in both groups. According to Comps et al. [35], supply of 200 micrograms of selenomethionine per day for 28 months caused no clinically significant changes in thyroid hormone concentrations. Similar results were presented by Rayman et al. [36], who supplemented 501 elderly HT patients with selenium (100, 200 and $300 \mathrm{mg}$ per day) for a period of six months. The study found no significant changes in thyroid function (TSH, FT4, FT3) in selenium-treated subjects. In addition, the average concentration of selenium in serum of patients with HT measured before the test were normal and remained at $91 \mathrm{mg} / \mathrm{l}$. Olivieri et al. [37] showed a significant decrease in the FT4 level in selenium-treated $(100 \mu \mathrm{g} /$ day) elderly subjects as compared to the control group. In view of these ambiguous results, routine supplementation of selenium in the prevention and treatment of hypothyroidism with respect to each population is not recommended. Moreover, many reports drew attention to the danger of administration of uncontrolled excessive doses of selenium.

\section{Vitamin D and Hashimoto's disease}

Vitamin D is responsible for the regulation of calciumphosphate homeostasis. It also affects cell proliferation and differentiation, insulin secretion and cardiac contractility. Furthermore, it controls the function of the immune system by decreasing the activity of T-cells and production of pro-inflammatory cytokines [8]. Vitamin D deficiency defined as serum 25(OH)D3 below $10 \mathrm{ng} / \mathrm{ml}$ is associated with the development of a variety of autoimmune diseases including HT. The case-control study [39] that included 161 patients with HT and 162 healthy controls showed that vitamin D deficiency in HT patients was significantly higher (148 of 161, 92\%) than in the healthy controls (102 of 162, 63\%, $p<0.0001$ ). Among patients with $\mathrm{HT}$, the occurrence of vitamin $\mathrm{D}$ deficiency showed a higher trend in overt hypothyroidism (47 of $50,94 \%$ ) or subclinical hypothyroidism (44 of $45,98 \%$ ) than in euthyroidism (57 of $66,86 \%$ ), but the differences were not significant ( $p=0.083$ ). Kivity et al. [40] demonstrated, that the prevalence of vitamin $\mathrm{D}$ deficiency (level above $10 \mathrm{ng} / \mathrm{ml}$ ) was significantly higher in patients with autoimmune thyroid diseases as compared with healthy individuals ( $72 \%$ vs. $30.6 \%$; $p<0.001$ ), as well as in patients with HT compared to patients with non-AITDs (79\% vs. 52\%; p < 0.05). Furthermore, vitamin $\mathrm{D}$ deficiency correlated width the presence of antithyroid antibodies $(p=0.01)$ and abnormal thyroid function tests $(P=0.059)$.

Camurdan et al. [41] in 2012 published a study evaluating the problem of vitamin $D$ deficiency in children with autoimmune thyroiditis. As in the case of the adult population, deficiency of $25(\mathrm{OH}) \mathrm{D} 3$ was more frequent in children with HT as compared to the control group (73.1\% vs. $17.6 \%, p<0.0001)$. In the group of children with Hashimoto's disease, mean 25(OH)D levels were significantly lower as compared with the control group $(31.2+/-11.5$ vs. $57.9+/-19.7 \mathrm{nmol} / \mathrm{L}, \mathrm{p}<0.001)$ and were inversely correlated with the anti-thyroid peroxidase (anti-TPO) levels ( $r=-0.30, p=0.007$ ). This research suggested that vitamin $D$ deficiency may play a role in the development of autoimmune response in Hashimoto's thyroiditis. Recent report [42] confirmed the results of the previous studies. In a group of patients suffering from HT in a euthyroid state, who were on a stable dose of L-thyroxine (the average level of vitamin D was $11.4 \pm 5.2 \mathrm{ng} / \mathrm{mL}$ and it was lower as compared to the control group $(15.4 \pm 6.8 \mathrm{ng} / \mathrm{mL}$, $p<0.001)$. Serum 25(OH)D levels directly correlated with thyroid volume $(r=0.145, p<0.001)$ and inversely correlated with anti-TPO $(r=-0.361, p<0.001)$ and anti-TG levels $(r=-0.335, p<0.001)$. The serum $25(\mathrm{OH}) \mathrm{D}$ levels $(10.3 \pm 4.58 \mathrm{ng} / \mathrm{mL})$ were significantly lower in female chronic HT patients as compared to male control subjects (19.3 $\pm 5.9 \mathrm{ng} / \mathrm{mL}, \mathrm{p}<0.001)$. From the presented data, it can be assumed, that vitamin D supplementation could reduce the incidence of HT and alleviate the disease. However, there is a need for further research on this topic.

\section{Conclusions}

Many previous studies confirmed the involvement of impaired antioxidant status and vitamin D deficiency in development of autoimmune diseases. Nevertheless, there is no sufficient proof confirming benefits of supplementation with vitamins and trace minerals for the treatment of Hashimoto's disease.

Because of the potential impact of vitamins A, C, $E$, selenium and zinc reducing oxidative stress as well as the effects of vitamin $D$ in reducing the serum antiTPO level, it is necessary to pay more attention to nutritional education of patients suffering from $\mathrm{HT}$.

\section{References}

1. Staii A, Mirocha S, Todorova-Koteva K, Glinberg S, Jaume JC. Hashimoto's thyroiditis is more frequent than expec- 
ted when diagnosed by cytology which uncovers a preclinical state. Thyroid Res. 2010;3(1):11.

2. Przybylik-Mazurek E, Hubalewska-Dydejczyk A, Huszno B. Niedoczynność tarczycy na tle autoimmunologicznym. Alergol Immunol. 2007;4,3(4):64-9.

3. Baretić M. 100 years of Hashimoto thyroiditis, still an intriguing disease. Acta Med Croatica. 2011;65(5):453-7.

4. Łącka K, Maciejewska A. Współczesne poglądy na temat etiopatogenezy autoimmunologicznego zapalenia tarczycy (choroby Hashimoto). Pol Merk Lek. 2011;30,176: 132-8.

5. Erdamar H, Demirci H, Yaman H, Erbil MK, Yakar T, Sancak $B$, et al. The effect of hypothyroidism, hyperthyroidism, and their treatment on parameters of oxidative stress and antioxidant status. Clin Chem Lab Med. 2008; 46(7):1004-10.

6. Reddy VS, Gouroju S, Suchitra MM, Suresh V, Sachan A, Srinivasa Rao PV, et al. Reddy VS Antioxidant defense in overt and subclinical hypothyroidism. Horm Metab Res. 2013;45(10):754-8.

7. Rostami R, Aghasi MR, Mohammadi A, Nourooz-Zadeh J. Enhanced oxidative stress in Hashimoto's thyroiditis: inter-relationships to biomarkers of thyroid function. Clin Biochem. 2013;46(4-5):308-12.

8. Ertek S, Cicero AF, Caglar O, Erdogan G. Relationship between serum zinc levels, thyroid hormones and thyroid volume following successful iodine supplementation. Hormones (Athens). 2010;9(3):263-8.

9. Erdal M, Sahin M, Hasimi A, Uckaya G, Kutlu M, Saglam $K$. Trace element levels in hashimoto thyroiditis patients with subclinical hypothyroidism. Biol Trace Elem Res. 2008;123(1-3):1-7.

10. Przybylik-Mazurek E, Zagrodzki P, Kuźniarz-Rymarz S, Hubalewska-Dydejczyk A. Thyroid disorders-assessments of trace elements, clinical, and laboratory parameters. Biol Trace Elem Res. 2011;141(1-3):65-75.

11. Betsy A, Binitha MP, Sarita S. Zinc Deficiency Associated with Hypothyroidism: An Overlooked Cause of Severe Alopecia. Int J Trichology. 2013;5(1):40-2.

12. Pathak $R$, Dhawan $D$, Pathak A. Effect of zinc supplementation on the status of thyroid hormones and $\mathrm{Na}, \mathrm{K}$, and Ca levels in blood following ethanol feeding. Biol Trace Elem Res. 2011;140(2):208-14.

13. Stolińska H, Wolańska D. Składniki pokarmowe istotne w niedoczynności tarczycy. Żyw Człow Metab. 2012; 39(3):222-9.

14. Deshpande UR, Joseph LJ, Patwardhan UN, Samuel AM. Effect of antioxidants (vitamin C, E and turmeric extract) on methimazole induced hypothyroidism in rats. Indian J Exp Biol. 2002;40(6):735-8.

15. Sarandöl E, Taş S, Dirican M, Serdar Z. Oxidative stress and serum paraoxonase activity in experimental hypothyroidism: effect of vitamin E supplementation. Cell Biochem Funct. 2005;23(1):1-8.

16. Adali M, Inal-Erden M, Akalin A, Efe B. Effects of propylthiouracil, propranolol, and vitamin E on lipid peroxidation and antioxidant status in hyperthyroid patients. Clin Biochem. 1999;32:363-7.

17. Farhangi MA, Keshavarz SA, Eshraghian M, Ostadrahimi A, Saboor-Yaraghi AA. The effect of vitamin A supplementation on thyroid function in premenopausal women. J Am Coll Nutr. 2012;31(4):268-74.
18. Hess SY. The impact of common micronutrient deficiencies on iodine and thyroid metabolism: the evidence from human studies. Best Pract Res Clin Endocrinol Metab. 2010;24(1):117-32.

19. Dellal FD, Niyazoglu M, Ademoglu E, Gorar S, Candam Z, Bekdemir H et al. Evaluation of Serum Trace Elements and Vitamin Levels in Hashimoto's Thyroiditis: Single Centre Experience from Turkey. OJEMD. 2013;3: 236-40.

20. Ness-Abramof R, Nabriski DA, Braverman LE, Shilo $L$, Weiss E, Reshef T, et al. Prevalence and Evaluation of B12 Deficiency in Patients with Autoimmune Thyroid Disease. N Am J Med Sci. 2006;332(3):119-22.

21. Sellin JH, Vassilopoulou-Sellin R. In: Braverman LE, Utiger RD (eds.). Werner \& Ingbar's the Thyroid, $8^{\text {th }}$ Edition. Lippincott Williams \& Wilkins, Philadelphia 2000: 622-6.

22. Moncayo R, Kroiss A, Oberwinkler M, Karakolcu F, Starzinger $M$, Kapelari $K$, et al. The role of selenium, vitamin $C$, and zinc in benign thyroid diseases and of selenium in malignant thyroiddiseases: Low selenium levels are found in subacute and silent thyroiditis and in papillary and follicular carcinoma. BMC Endocr Disord. 2008;25;8:2.

23. Socha K, Dziemianowicz M, Omeljaniuk W. Nawyki żywieniowe a stężenie selenu w surowicy u pacjentów z chorobą Hashimoto. Probl Hig Epidemiol. 2012;93(4):824-7.

24. Erdal M, Sahin M, Hasimi A, Uckaya G, Kutlu M, Saglam $\mathrm{K}$. Trace element levels in Hashimoto thyroiditis patients with subclinical hypothyroidism. Biol Trace Elem Res. 2008;123(1-3):1-7.

25. Schomburg L. Selenium, selenoproteins and the thyroid gland: interactions in health and disease. Nat Rev Endocrinol. 2011;8(3):160-71.

26. van Zuuren EJ, Albusta AY, Fedorowicz Z, Carter B, Pijl H. Selenium supplementation for Hashimoto's thyroiditis. Cochrane Database Syst Rev. 2013;6.

27. Drutel A, Archambeaud F, Caron P. Selenium and the thyroid gland: more good news for clinicians. Clin Endocrinol (Oxf). 2013;78(2):155-64.

28. Zhu L, Bai X, Teng WP, Shan ZY, Wang WW, Fan CL, et al. Effects of selenium supplementation on antibodies of autoimmune thyroiditis. Zhonghua Yi Xue Za Zhi. 2012;92(32):2256-60.

29. Toulis KA, Anastasilakis AD, Tzellos TG, Goulis DG, Kouvelas $D$. Selenium supplementation in the treatment of Hashimoto's thyroiditis: a systematic review and a metaanalysis. Thyroid. 2010;20(10):1163-73.

30. Turker O, Kumanlioglu K, Karapolat I, Dogan I. Selenium treatment in autoimmune thyroiditis: 9-month follow-up with variable doses. J Endocrinol. 2006;190(1):151-6.

31. Gartner R, Gasnier BCH. Selenium in the treatment of autoimmune thyroiditis. Biofactors. 2003;19:165-70.

32. Mazokopakis EE, Papadakis JA, Papadomanolaki MG, Batistakis AG, Giannakopoulos TG, Protopapadakis $E E$, et al. Effects of 12 months treatment with L-selenomethionine on serum anti-TPO Levels in Patients with Hashimoto'sthyroiditis. Thyroid. 2007;17(7):609-12.

33. Bhuyan AK, Sarma D, Saikia UK. Selenium and the thyroid: A close-knit connection. Indian J Endocrinol Metab. 2012;16(Suppl 2):354-5.

34. Gärtner R, Gasnier BC, Dietrich JW, Krebs B, Angstwurm MW. Selenium supplementation in patients 
with autoimmune thyroiditis decreases thyroid peroxidase antibodiesconcentrations. J Clin Endocrinol Metab. 2002;87(4):1687-91.

35. Combs GF, Midthune DN, Patterson KY, Canfield WK Hill $A D$, Levander $O A$, et al. Effects of selenomethionine supplementation on selenium status and thyroid hormone concentrations in healthy adults. Am J Clin Nutr. 2009;89(6):1808-14.

36. Rayman MP, Thompson AJ, Bekaert B, Catterick J, Galassini $R$, Hall $E$, et al. Randomized controlled trial of the effect of selenium supplementation on thyroid function in the elderly in theUnited Kingdom. Am J Clin Nutr. 2008;87(2):370-8.

37. Olivieri O, Girelli D, Azzini M, Stanzial AM, Russo C, Ferroni $M$, et al. Low selenium status in the elderly influences thyroid hormones. Clin Sci (Lond). 1995;89(6):637-42.

38. Łącka K, Maciejewski A. Udział witaminy D w etiopatogenezie autoimmunologicznego zapalenia tarczycy. Pol Merk Lek. 2013;34(203):281-5.

39. Tamer G, Arik S, Tamer I, Coksert D. Relative vitamin $D$ insufficiency in Hashimoto's thyroiditis. Thyroid. 2011;21(8):891-6.
40. Kivity S, Agmon-Levin N, Zisappl M, Shapira Y, Nagy EV, Dankó $K$, et al. Vitamin D and autoimmune thyroid diseases.Cell Mol Immunol. 2011;8(3):243-7.

41. Camurdan OM, Döğer E, Bideci A, Celik N, Cinaz P. Vitamin $D$ status in children with Hashimoto thyroiditis. J Pediatr Endocrinol Metab. 2012;25(5-6):467-70.

42. Bozkurt NC, Karbek B, Ucan B, Sahin M, Cakal E, Ozbek $M$, et al. The association between severity of vitamin D deficiency and Hashimoto's thyroiditis. Endocr Pract. 2013;19(3):479-84.

Correspondence address: Małgorzata Włochal Department of Internal Diseases, Metabolic Disorders and Nutrition Poznan University of Medical Sciences 49 Przybyszewskiego Street 60-355 Poznań, Poland phone/fax: +48 618691314 email: malgorzata_wlochal@o2.pl 